Check for updates

Cite this: RSC Adv., 2019, 9, 21116

\title{
Tuning two-electron transfer in terpyridine-based platinum(II) pincer complexes $\uparrow$
}

\author{
Seher Kuyuldar, (D) ab Clemens Burda (D) *b and William B. Connick t $^{a}$
}

An important factor in obtaining reversible multi-electron transfer is overcoming large changes in coordination geometry. One strategy is to use ligands that can support the geometries favored before and after the electron transfer. $\mathrm{Pip}_{2} \mathrm{NCN}^{-}$pincer and terpyridine ligands are used to support square planar Pt(॥) and octahedral Pt(Iv). For the Pt(॥) complexes, $\left[\mathrm{Pt}\left(\mathrm{Z}-\mathrm{pip}_{2} \mathrm{NCN}\right)(\mathrm{R}-\mathrm{tpy})\right]^{+}\left(\mathrm{Z}=\mathrm{NO}_{2}, \mathrm{MeO}, \mathrm{H} ; \mathrm{R}\right.$ $=\mathrm{H}$, tertyl butyl, tolyl), ${ }^{1} \mathrm{H}$ NMR spectroscopy shows that the $\mathrm{Z}-\mathrm{pip}_{2} \mathrm{NCN}^{-}$ligand is monodentate whereas the R-terpyridyl ligand is tridentate. The availability of flanking piperidyl groups of the monodentate pincer ligand is essential for the stabilization of the metal center upon oxidation. Pt(Z$\left.\operatorname{pip}_{2} \mathrm{NCN}\right)\left(\mathrm{R}\right.$-tpy) ${ }^{+}$complexes undergo two-electron platinum centered oxidation near $0.4 \mathrm{~V}$ and two $\mathrm{Pt}(\mathrm{tpy})$ centered reductions near $-1.0 \mathrm{~V}$ and $-1.5 \mathrm{~V}$. An estimate of $n_{\mathrm{ox}} / n_{\text {red }}=1.8$ is consistent with an oxidation that involves two-electron transfer per Pt center. Variation in the pincer-( $Z$ ) and terpyridine-(R) substituents allows for tuning of the oxidation process over a $260 \mathrm{mV}$ range and the two reduction processes over ranges of $230 \mathrm{mV}$ (first reduction) and $290 \mathrm{mV}$ (second reduction step).

Received 24th May 2019

Accepted 24th June 2019

DOI: 10.1039/c9ra03939b

rsc.li/rsc-advances
An important factor in obtaining reversible multi-electron transfer is overcoming large changes in coordination geometry. One strategy is to use ligands that can support the geometries favored by both oxidation states. ${ }^{7-16}$ Reversible outersphere two-electron transfer platinum and palladium complexes that utilize stabilization of $\mathrm{Pt}(\mathrm{II}) / \mathrm{Pd}(\mathrm{II})$ and $\mathrm{Pt}(\mathrm{IV}) /$ $\operatorname{Pd}(\mathrm{Iv})$ oxidation states with suitable ligands have been described recently. ${ }^{4,17}$ In the case of the platinum complex, $\mathrm{Pt}\left(\mathrm{pip}_{2} \mathrm{NCN}\right)(\mathrm{tpy})^{+}$, the $\mathrm{d}^{8}$ square planar $\mathrm{Pt}(\mathrm{II})$ is coordinated to $\operatorname{pip}_{2} \mathrm{NCN}^{-}$(pip2NCNH $=1,3$-bis(piperdylmethyl)benzene) in a monodentate fashion through the central binding site while tpy $\left(2,2^{\prime}: 6^{\prime}, 2^{\prime \prime}\right.$-terpyridine) is tridentate (Chart 1). Upon twoelectron oxidation, the $\mathrm{d}^{6}$ octahedral $\mathrm{Pt}(\mathrm{Iv})$ complex $\mathrm{Pt}\left(\mathrm{pip}_{2^{-}}\right.$ NCN)(tpy) ${ }^{3+}$ forms. The oxidized complex binds both $\mathrm{pip}_{2} \mathrm{NCN}^{-}$

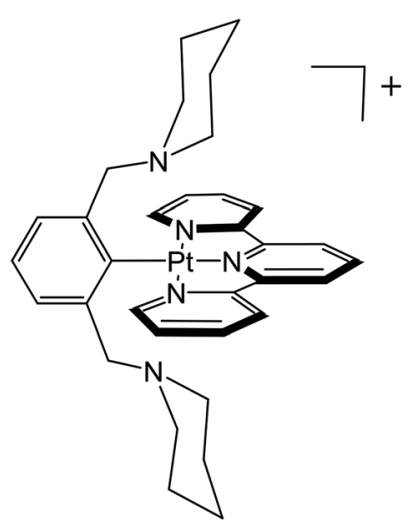

Chart 1 The $\left[\mathrm{Pt}\left(\mathrm{pip}_{2} \mathrm{NCN}\right)(\mathrm{tpy})\right]^{+}$complex with tridentate tpy and monodentate $\mathrm{pip}_{2} \mathrm{NCN}$ ligand before two-electron oxidation.

\footnotetext{
${ }^{a}$ University of Cincinnati, Department of Chemistry, 2600 Clifton Ave., Cincinnati, OH 45221, USA

${ }^{b}$ Case Western Reserve University, Department of Chemistry, 10900 Euclid Ave., Cleveland, OH 44106, USA.E-mail: burda@case.edu

$\dagger$ Electronic supplementary information (ESI) available. See DOI: 10.1039/c9ra03939b

‡ William B. Connick passed away in 2018.
} respectively, has been shown to be effective in generating transfer has been reported for a few ruthenium complexes such as reversible oxidation of $\left[\mathrm{Ru}^{\mathrm{III}}\left(\mathrm{NH}_{3}\right)_{6}\right]^{3+}$ to $\left[\mathrm{Ru}^{\mathrm{V}}\left(\mathrm{NH}_{3}\right)_{6}\right]^{5+}$ (ref. 5) and trans- $\left[\mathrm{Ru}^{\mathrm{II}}(\mathrm{tpy})(\mathrm{CN}-\mathrm{Me})\left(\mathrm{OH}_{2}\right)\right]^{2+}$ to $\left[\mathrm{Ru}^{\mathrm{IV}}(\mathrm{tpy})(\mathrm{CN}-\right.$ $\mathrm{Me})(=\mathrm{O})]^{4+}{ }^{6}$ 
and tpy ligands tridentate, occupying all six binding sites around the platinum cation.

In contrast to well-studied platinum systems, ${ }^{18-26}$ which undergo irreversible metal-centered redox processes, the remarkable reversibility of the redox chemistry of $\mathrm{Pt}\left(\mathrm{pip}_{2}-\right.$ $\mathrm{NCN})\left(\right.$ tpy) ${ }^{+}$is suggestive of a non-covalent interaction between the $\operatorname{pip}_{2} \mathrm{NCN}^{-}$amine groups and the $\mathrm{Pt}(\mathrm{II})$ metal center, which effectively preorganizes the square planar complex for electron transfer and formation of the $\operatorname{Pt}(\mathrm{vI})$ octahedral geometry. The notion of preorganization is supported by crystal structures of a series of two-electron reagents which reveal relatively short $\mathrm{Pt} \cdots \mathrm{N}$ (piperidyl) distances. ${ }^{4,27}$ In addition, UV-visible absorption spectra of these complexes exhibit long wavelength absorption features $(>500 \mathrm{~nm})$, which are absent from the spectra of complexes without Pt $\cdots \mathrm{N}$ (piperidyl) interactions, such as $\left[\mathrm{Pt}(\text { tpy)(phenyl) }]^{+} .27\right.$

In order to investigate the role of metal acidity on the redox potentials, we report the synthesis and redox chemistry of platinum complexes with electron-releasing and withdrawing groups $\left(\mathrm{Z}=\mathrm{MeO}, \mathrm{NO}_{2}\right)$ at the para-positions of the pivoting $\operatorname{pip}_{2} \mathrm{NCN}^{-}$ligand and the $4^{\prime}$-substituted positions of the tridentate tpy ligand $\left(\mathrm{R}=t\right.$-butyl $\left(\mathrm{C}\left(\mathrm{CH}_{3}\right)_{3}\right)$, tolyl (4-metylphenyl)) (Chart 2).

\section{Results and discussion}

\section{Synthesis and ${ }^{1} \mathrm{H}$ NMR Spectroscopy}

Platinum(II) complexes with a para substituted $\mathrm{NCN}^{-}$pincer ligand and a terpyridyl ligand (tpy, ${ }^{t} \mathrm{Bu}_{3}$ tpy or toltpy) have been prepared (Chart 2). The synthesis of the Z-pip ${ }_{2} \mathrm{NCNBr}$ ligand precursors and their corresponding $\mathrm{Pt}\left(\mathrm{Z}\right.$-pip $\left.{ }_{2} \mathrm{NCN}\right) \mathrm{Br}$ complexes along with their ${ }^{1} \mathrm{H}$ NMR spectra are provided in the ESI (Scheme S1, Fig. S1 and S2 $\dagger$ ).

The synthetic route to two-electron platinum reagents with $\mathrm{NCN}^{-}$and terpyridyl ligands involves treatment of an acetone solution of $\mathrm{Pt}\left(\mathrm{Z}-\mathrm{pip}_{2} \mathrm{NCN}\right) \mathrm{Br}$ with a suitable silver salt (e.g., $\mathrm{AgBF}_{4}$ ), followed by filtration (Scheme 1). Within 15 minutes of adding one equivalent of tpy, ${ }^{t} \mathrm{Bu}_{3}$ tpy or toltpy to the filtrate, the pale yellow solution turns orange or red, indicating displacement of the piperidyl groups by the terpyridyl ligand. Full

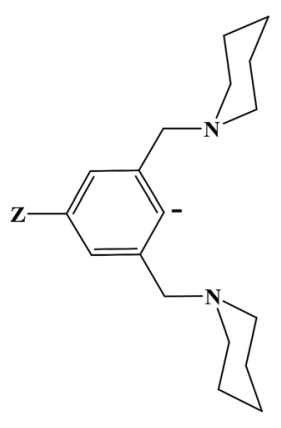

Z-pip ${ }_{2} \mathrm{NCN}^{-}$

$\mathrm{Z}=\mathrm{NO}_{2}, \mathrm{MeO}, \mathrm{H}$

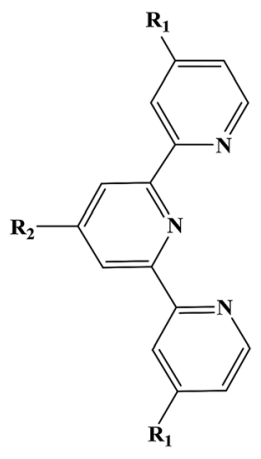

R- tpy $\mathrm{R}_{1}=\mathrm{H},{ }^{\mathrm{t}}$ Butyl; $\mathrm{R}_{2}=\mathrm{H},{ }^{\mathrm{t}} \mathrm{Buty}$, tolyl
Chart 2 Tridentate ligands prepared for this study. experimental details and characterization by ${ }^{1} \mathrm{H}$ NMR spectroscopy and mass spectrometry are given in the ESI (Fig. S3†).

Interestingly, though solutions of the four complexes are red, their colors vary in the solid state from yellow $\left[\mathrm{Pt}\left(\mathrm{pip}_{2}-\right.\right.$ $\mathrm{NCN})\left({ }^{t} \mathrm{Bu}_{3}\right.$ tpy $\left.)\right]\left(\mathrm{BF}_{4}\right)$ and $\left[\mathrm{Pt}\left(\mathrm{NO}_{2}-\mathrm{pip}_{2} \mathrm{NCN}\right)(\right.$ tpy $\left.)\right]\left(\mathrm{BF}_{4}\right)$ to orangered $\left[\mathrm{Pt}\left(\mathrm{MeO}-\mathrm{pip}_{2} \mathrm{NCN}\right)(\mathrm{tpy})\right] \mathrm{OTf}$ and $\left[\mathrm{Pt}\left(\mathrm{pip}_{2} \mathrm{NCN}\right)(\right.$ toltpy $\left.)\right]\left(\mathrm{BF}_{4}\right)$.

The coordination geometry illustrated in Scheme 1, in which the tpy ligand is tridentate and the $\mathrm{Z}-\mathrm{pip}_{2} \mathrm{NCN}^{-}$ligand is monodentate, is confirmed in the ${ }^{1} \mathrm{HNMR}$ spectra of the complexes by (1) the presence of ${ }^{195} \mathrm{Pt}$ satellites associated with the $\alpha$-tpy proton $(\mathrm{G})$ resonance, (2) the absence of ${ }^{195} \mathrm{Pt}$ satellites on the benzylic proton (C) resonance, and (3) the appearance of a single $\alpha$-piperidyl proton (D) resonance (Fig. 1). The substituents on $\operatorname{pip}_{2} \mathrm{NCN}^{-}(\mathrm{Z})$ and tpy (R) ligands exert the greatest influence on nearest neighbor protons. For instance, substituting $\mathrm{MeO}$ for $\mathrm{NO}_{2}$ causes the meta-phenyl proton resonance to shift upfield by $1.1 \mathrm{ppm}$. Similarly, substitution of $t$ butyl groups on tpy, shifts the nearby terpyridyl $\mathrm{J}$ and $\mathrm{K}$ proton resonances upfield by $0.26 \mathrm{ppm}$. Changes in the $\mathrm{Z}$ and $\mathrm{R}$ substituents have little influence on the chemical shifts of the benzylic and piperidyl resonances.

Interestingly, the $\operatorname{pip}_{2} \mathrm{NCN}^{-} \mathrm{NO}_{2}$ and terpyridyl $t$-butyl substituents shift the G proton resonances upfield by $0.17 \mathrm{ppm}$, whereas the pip $_{2} \mathrm{NCN}^{-} \mathrm{MeO}$ shifts $\mathrm{G}$ downfield by $0.15 \mathrm{ppm}$ and terpyridyl tolyl substituent does not shift it at all. The influence of the $t$-butyl group is consistent with its comparative electronreleasing properties. However, the origin of the effect of the $\mathrm{NO}_{2}$ and $\mathrm{MeO}$ substituents is more surprising since their electron withdrawing or donating properties are expected to have an opposite influence (decrease and increase, respectively) on the electron density of the platinum center and terpyridyl ligand through inductive effects. The $\mathrm{MeO}$ and $\mathrm{NO}_{2}$ substituents shift the remaining terpyridyl resonances upfield and downfield, respectively, by $\leq 0.07 \mathrm{ppm}$.

Mediation of electron donor properties through a metal has been investigated by different researchers. For a series of $\mathrm{Ru}(\mathrm{X}$ tpy) $(\mathrm{Y} \text {-tpy })^{2+}$ complexes $(\mathrm{X}, \mathrm{Y}=$ substituents on the para position of the central pyridine, i.e., $\mathrm{NO}_{2}, \mathrm{NH}_{2}, \mathrm{Cl}$ ) in acetone, Constable et al. reported that the chemical shifts of each tpy ligand are independent of the substituent on the other ligand. ${ }^{28}$ However, Fallahpour et al. observed that the substituent on one of the tpy

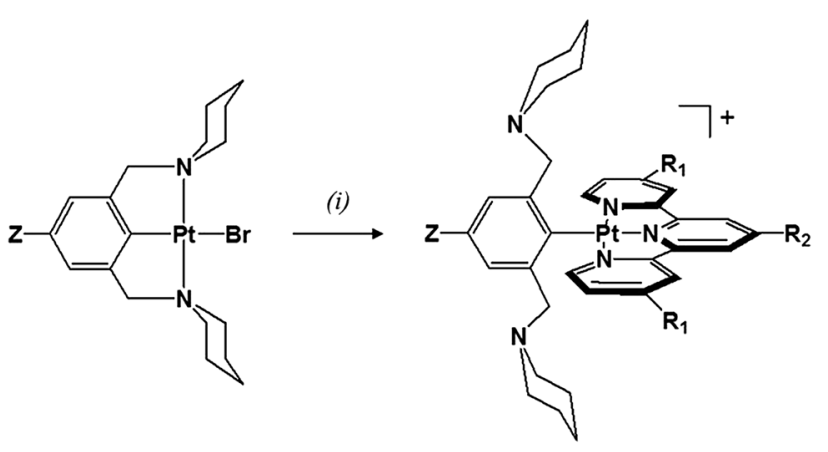

Scheme 1 Synthesis of platinum(॥) complexes $\left(\mathrm{Z}=\mathrm{H}, \mathrm{NO}_{2}, \mathrm{MeO} ; \mathrm{R}_{1}=\right.$ $\mathrm{H}$, $t$-butyl; $\mathrm{R}_{2}=\mathrm{H}, t$-butyl, tolyl) with two potentially meridionalcoordinating tridentate ligands: (i) $\mathrm{AgBF}_{4}$ or AgOTf; tpy, ${ }^{t} \mathrm{Bu}_{3} \mathrm{tpy}$ or toltpy; acetone. 

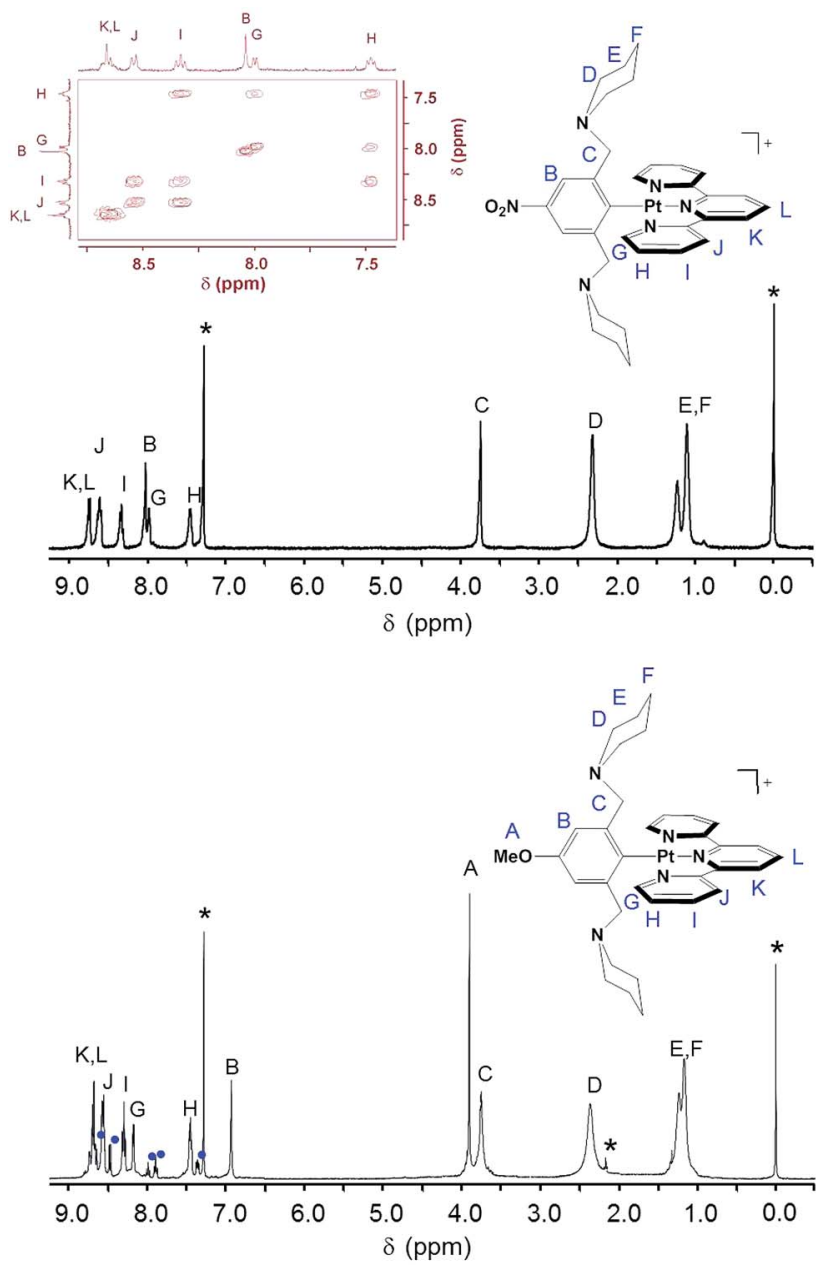

Fig. $1{ }^{1} \mathrm{H}$ NMR spectra of $\left[\mathrm{Pt}\left(\mathrm{NO}_{2}-\right.\right.$ pip $\left.\left._{2} \mathrm{NCN}\right)(\mathrm{tpy})\right]\left(\mathrm{BF}_{4}\right)$ (top) and [Pt(MeO$\mathrm{pip}_{2} \mathrm{NCN}$ )(tpy)] Otf (bottom) in $\mathrm{CDCl}_{3}$. Aromatic region of the COSY spectrum of $\left[\mathrm{Pt}\left(\mathrm{NO}_{2}-\mathrm{pip}_{2} \mathrm{NCN}\right)(\mathrm{tpy})\right]\left(\mathrm{BF}_{4}\right)$ in $\mathrm{CDCl}_{3}$ is shown embedded into the top spectrum. The asterisks * denote $\mathrm{CHCl}_{3}(7.26 \mathrm{ppm})$, acetone (2.17 ppm) and TMS (0.0 ppm) and denote free tpy impurities (8.728.62 ppm, 8.46 ppm, 7.97 ppm, 7.88 ppm and 7.35 ppm).

ligands influences certain resonances on the other tpy for a series of similar $\mathrm{Ru}$ (II) and Fe(II) complexes in acetonitrile. ${ }^{29}$

Interestingly, they report that the resonance that is most sensitive to substituent effects changes depending on the metal. For instance, replacing one of the $\mathrm{NH}_{2}$-tpy ligands with $\mathrm{NO}_{2}$-tpy in $\mathrm{Ru}\left(\mathrm{NH}_{2} \text {-tpy }\right)_{2}{ }^{2+}$ shifts the $\alpha$-pyridyl resonance (G) of the other $\mathrm{NH}_{2}$-tpy ligand downfield by $0.2 \mathrm{ppm}$, but the effect of the same replacement in $\mathrm{Fe}\left(\mathrm{NH}_{2} \text {-tpy }\right)_{2}{ }^{2+}$ is a downfield shift of only $0.02 \mathrm{ppm}$. From these observations, we suggest that the mediation of electron donor properties of a substituent on a ligand to another ligand is influenced by the metal, solvent, type of ligand and coordination geometry.

$\mathrm{Pt}\left(\mathrm{pip}_{2} \mathrm{NCN}\right)(\mathrm{tpy})^{+}$is reported to be unstable in acetonitrile solution with an half-life of $\sim 2$ hours. The tpy ligand is dissociated to form a $\mathrm{Pt}\left(\mathrm{pip}_{2} \mathrm{NCN}\right)(\text { solvent })^{+}$adduct. $^{4} \mathrm{Pt} \mathrm{pip}_{2^{-}}$ $\mathrm{NCN})\left({ }^{t} \mathrm{Bu}_{3} \text { tpy }\right)^{+}$is considerably more stable in acetonitrile. The loss in the intensity of the $420 \mathrm{~nm}$ electronic absorption band is consistent with $3 \%$ decomposition in one hour. The increased stability of the ${ }^{t} \mathrm{Bu}_{3}$ tpy complex is attributable to the comparatively greater electron-donor properties of the ${ }^{t} \mathrm{Bu}_{3}$ tpy ligand, which are anticipated to decrease the electrophilicity of the metal center and thereby increase the reaction barrier of an associative mechanism. This observation implicates modulation of ligand electron-donor properties as an effective strategy for tuning the relative stabilities of two-electron platinum reagents.

Each piperidyl group of $\mathrm{Pt}\left(\mathrm{pip}_{2} \mathrm{NCN}\right)\left({ }^{t} \mathrm{Bu}_{3} \text { tpy }\right)^{+}$was readily protonated by dropwise addition of $1 \mathrm{M} \mathrm{HNO}_{3}$ to the deep red acetone solution of the complex until the solution turned bright yellow. The ${ }^{1} \mathrm{H}$ NMR spectrum of the protonated complex is given in the ESI (Fig. S3 $\dagger$ ). However, attempts to protonate the other complexes with substituted pincer ligands did not yield similar diprotonated compounds. In the case of $\mathrm{Pt}\left(\mathrm{MeO}-\mathrm{pip}_{2}{ }^{-}\right.$ $\mathrm{NCN})\left({ }^{t} \mathrm{Bu}_{3} \text { tpy }\right)^{+}$, the product obtained from treatment with acetic acid gave a platinum(Iv) salt, $\left[\mathrm{Pt}(\mathrm{tpy})\left(\mathrm{CH}_{3} \mathrm{COO}\right)_{3}\right]\left(\mathrm{PF}_{6}\right)$ with a rare tridentate terpyridine and three monodentate acetate groups. ${ }^{30}$ In the case of $\left[\mathrm{Pt}\left(\mathrm{NO}_{2}-\mathrm{pip}_{2} \mathrm{NCN}\right)(\text { tpy })\right]^{+}$, treatment with acid caused dissociation of the terpyridine ligand, as determined by ${ }^{1} \mathrm{H}$ NMR spectroscopy.

\section{Electronic spectroscopy}

To assess the influence of the pincer piperidyl groups on the electronic structures of these complexes, UV-visible absorption spectra were recorded of dichloromethane solutions of $\left[\mathrm{Pt}(\mathrm{Ph})\left({ }^{t} \mathrm{Bu}_{3} \mathrm{tpy}\right)\right]\left(\mathrm{BF}_{4}\right), \quad\left[\mathrm{Pt}\left(\mathrm{pip}_{2} \mathrm{NCN}\right)\left({ }^{t} \mathrm{Bu}_{3}\right.\right.$ tpy $\left.)\right]\left(\mathrm{BF}_{4}\right), \quad\left[\mathrm{Pt}\left(\mathrm{pip}_{2^{-}}\right.\right.$ $\mathrm{NCN})($ toltpy) $]\left(\mathrm{BF}_{4}\right)$ and $\left[\mathrm{Pt}\left(\mathrm{NO}_{2}-\mathrm{pip}_{2} \mathrm{NCN}\right)(\right.$ tpy)$\left.)\right]\left(\mathrm{BF}_{4}\right)$ (Fig. 2 and Table $\mathrm{S} 1$ in the $\mathrm{ESI}+) .\left[\mathrm{Pt}(\mathrm{Ph})\left({ }^{t} \mathrm{Bu}_{3} \mathrm{tpy}\right)\right]\left(\mathrm{BF}_{4}\right)$ and $\left[\mathrm{Pt}\left(\mathrm{pip}_{2^{-}}\right.\right.$ $\mathrm{NCN})\left({ }^{t} \mathrm{Bu}_{3}\right.$ tpy $\left.)\right]\left(\mathrm{BF}_{4}\right)$ are yellow solids whereas $\left[\mathrm{Pt}\left(\mathrm{pip}_{2}{ }^{-}\right.\right.$ $\mathrm{NCN})($ toltpy $)]\left(\mathrm{BF}_{4}\right)$ and $\left[\mathrm{Pt}\left(\mathrm{NO}_{2}-\mathrm{pip}_{2} \mathrm{NCN}\right)(\right.$ tpy $\left.)\right]\left(\mathrm{BF}_{4}\right)$ are orange solids. $\left[\mathrm{Pt}(\mathrm{Ph})\left({ }^{t} \mathrm{Bu}_{3}\right.\right.$ tpy $\left.)\right]\left(\mathrm{BF}_{4}\right)$ dissolves to give yellow solutions, whereas the two-electron reagents dissolve to give red solutions. The UV-visible absorption spectra of the terpyridyl complexes are qualitatively similar for wavelengths $<500 \mathrm{~nm}$, consistent with previous studies. ${ }^{31-37}$ For example, each complex exhibits intense absorption bands between $200 \mathrm{~nm}$ and $300 \mathrm{~nm}$

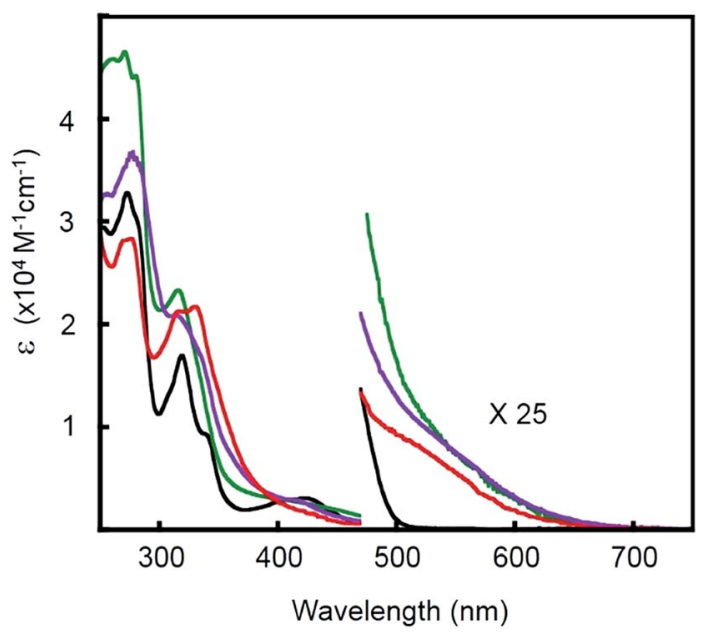

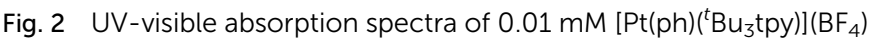

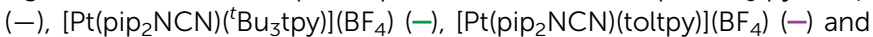
$\left[\mathrm{Pt}\left(\mathrm{NO}_{2}-\mathrm{pip}_{2} \mathrm{NCN}\right)(\mathrm{tpy})\right]\left(\mathrm{BF}_{4}\right)(-)$ in dichloromethane. 
(>30 $000 \mathrm{M}^{-1} \mathrm{~cm}^{-1}$ ). Platinum(II) terpyridyl complexes, such as $\operatorname{Pt}\left({ }^{t} \mathrm{Bu}_{3}\right.$ tpy $) \mathrm{Cl}^{+} \quad\left(215 \mathrm{~nm}, 46000 \quad \mathrm{M}^{-1} \quad \mathrm{~cm}^{-1} ; 256 \mathrm{~nm}\right.$, $45100 \mathrm{M}^{-1} \mathrm{~cm}^{-1}$; $282 \mathrm{~nm}, 33700 \mathrm{M}^{-1} \mathrm{~cm}^{-1}$; in acetonitrile) $)^{38}$ and $\mathrm{Pt}$ pincer complexes such as $\mathrm{Pt}\left(\mathrm{pip}_{2} \mathrm{NCN}\right) \mathrm{Cl}(275 \mathrm{~nm}$, $9050 \mathrm{M}^{-1} \mathrm{~cm}^{-1}$; in dichloromethane $)^{39}$ give rise to intense bands in this region. The moderately intense bands observed between 300-365 $\mathrm{nm}$ and the low intensity band observed near $425 \mathrm{~nm}$ are similar to those observed for other $\mathrm{Pt}(\mathrm{II}) \mathrm{pip}_{2} \mathrm{NCN}^{-}$ or phenyl complexes with terpyridyl ligands. These features have been assigned to $\pi \rightarrow \pi^{*}$ transitions associated with the tpy ligand and spin allowed $5 \mathrm{~d}(\mathrm{Pt}) \rightarrow \pi^{*}$ (tpy) MLCT transitions, respectively. ${ }^{27}$ The red shift in the transitions near $425 \mathrm{~nm}$ from where similar absorption features occur in $\mathrm{Pt}(\mathrm{II})$ terpyridine complexes, such as $\mathrm{Pt}\left({ }^{t} \mathrm{Bu}_{3} \mathrm{tpy}\right) \mathrm{Cl}\left(373 \mathrm{~nm}, 3990 \mathrm{M}^{-1} \mathrm{~cm}^{-1}\right.$; $386 \mathrm{~nm}, 3530 \mathrm{M}^{-1} \mathrm{~cm}^{-1}$ in acetonitrile) ${ }^{38}$ and $\mathrm{Pt}(\mathrm{tpy}) \mathrm{Cl}(372 \mathrm{~nm}$, $1300 \mathrm{M}^{-1} \mathrm{~cm}^{-1}$; $398 \mathrm{~nm}, 1800 \mathrm{M}^{-1} \mathrm{~cm}^{-1}$ in acetonitrile), ${ }^{34}$ is consistent an aryl group. For all complexes, a weak shoulder is observed near $500 \mathrm{~nm}$ in the tail of the ${ }^{1}$ MLCT transition. As expected from a corresponding ${ }^{3}$ MLCT transition, this feature is shifted 2000 to $3500 \mathrm{~cm}^{-1}$ to the red of the ${ }^{1}$ MLCT maximum. ${ }^{38,40,41}$ The apparent singlet-triplet MLCT splitting is in agreement with that observed for $\mathrm{Pt}\left({ }^{t} \mathrm{Bu}_{3} \mathrm{tpy}\right) \mathrm{Cl}\left(4800 \mathrm{~cm}^{-1}\right)^{38}$ and $\quad \operatorname{Pt}\left(6\right.$-phenyl-2,2'-bipyridine)(4-aminopyridine) ${ }^{+}$ $\left(2000 \mathrm{~cm}^{-1}\right) .{ }^{40}$

In the spectra of $\mathrm{Pt}\left(\mathrm{pip}_{2} \mathrm{NCN}\right)\left({ }^{t} \mathrm{Bu}_{3} \mathrm{tpy}\right)^{+}, \mathrm{Pt}\left(\mathrm{pip}_{2} \mathrm{NCN}\right)(\text { toltpy })^{+}$ and $\mathrm{Pt}\left(\mathrm{NO}_{2}-\mathrm{pip}_{2} \mathrm{NCN}\right)(\mathrm{tpy})^{+}$, there is an additional long wavelength absorption feature appearing near $550 \mathrm{~nm}$ $\left(\sim 300 \mathrm{M}^{-1} \mathrm{~cm}^{-1}\right)$. This weak band is absent from the spectra of model complexes such as $\mathrm{Pt}(\mathrm{Ph})\left({ }^{t} \mathrm{Bu}_{3} \mathrm{tpy}\right)^{+}$. In fact, this band has been observed for only the $\left[\mathrm{Pt}\left(\mathrm{pip}_{2} \mathrm{NCN}\right)(\mathrm{R}-\mathrm{tpy})\right]^{+}$complexes and is proposed to be the result of a weak interaction between the $\mathrm{N}$ (piperidyl) groups and the platinum center. This hypothesis is supported by the fact that this feature is not observed if the piperidyl groups are placed further away from the platinum center, as in $\left[\mathrm{Pt}\left(3,5-\mathrm{pip}_{2} \mathrm{NCN}\right)(\mathrm{tpy})\right]^{+},{ }^{27}$ or when the piperidyl groups are protected by protonation, as in $\mathrm{Pt}\left(\mathrm{pip}_{2} \mathrm{NCNH}_{2}\right)(-$ $\left.{ }^{t} \mathrm{Bu}_{3} \mathrm{tpy}\right)^{3+}$. The $\mathrm{sp}^{3}$ hybridized $\mathrm{N}$ (piperidyl) lone-pair orbital is expected to combine with the $6 \mathrm{p}_{z}(\mathrm{Pt})$ orbital to give rise to a filled $\sigma(\mathrm{Pt}-\mathrm{N})$ orbital and an empty $\sigma(\mathrm{Pt}-\mathrm{N})^{*}$ orbital. These axial interactions also are expected to destabilize the metal $\mathrm{d}$ orbitals, especially the $\mathrm{d}_{z^{2}}(\mathrm{Pt})$ level, resulting in a red-shift in MLCT transitions, as previously noted for other platinum(II) complexes with dangling nucleophiles. ${ }^{42}$ The presence of a new long-wavelength absorption band is suggestive of a $\sigma(\mathrm{Pt}-\mathrm{N}) \rightarrow$ $\pi^{*}$ (tpy) charge-transfer transition. The influence of piperidyl and terpyridyl substituents on the energy of this transition is consistent with this assignment. Substitution of $\mathrm{NO}_{2}$ for $\mathrm{H}$ on the $\operatorname{pip}_{2} \mathrm{NCN}^{-}$ligand and substitution of $t$-butyl groups for $\mathrm{H}$ on the terpydiyl ligand cause the band to blue shift $7600 \mathrm{~cm}^{-1}$ and $5100 \mathrm{~cm}^{-1}$, respectively. By contrast, substitution of a tolyl group for $\mathrm{H}$ on the terpyridyl ligand causes the band to red shift by $3900 \mathrm{~cm}^{-1}$. The influence of the $\mathrm{Z}$ substituents is consistent with modulation of the energy of the $\sigma(\mathrm{Pt}-\mathrm{N})$ level, whereas the influence of the $\mathrm{R}$ substituents is largely through modulations of the $\pi^{*}$ (tpy) level. These results also give deeper insight into the relation between the colors of these two-electron reagents and the stability of the charge-transfer states since the $t$-butyl substituents are anticipated to raise the $\pi^{*}$ (tpy) level, which further destabilizes the charge-transfer transition.

In keeping with this description, we note that $\left[\mathrm{Pt}\left(\mathrm{pip}_{2}-\right.\right.$ $\left.\mathrm{NCNH}_{2}\right)\left({ }^{t} \mathrm{Bu}_{3}\right.$ tpy) $]\left(\mathrm{PF}_{6}\right)_{3}$ is a yellow solid that dissolves to give yellow solutions (Fig. S3, and Table S1 $\dagger$ ). The spectrum is identical to that obtained when two equivalents of TFA (triflouroacidic acid) are added to an acetonitrile solution of $\left[\mathrm{Pt}\left(\mathrm{pip}_{2} \mathrm{NCN}\right)\left({ }^{t} \mathrm{Bu}_{3} \mathrm{tpy}\right)\right]\left(\mathrm{BF}_{4}\right)$. During the addition of acid, the intensities of the low-energy absorption bands $(>400 \mathrm{~nm})$ decrease, whereas a band at $382 \mathrm{~nm}$ emerges. Additionally, small shifts observed at wavelengths $<350 \mathrm{~nm}$, and the overall spectrum becomes qualitatively similar to that of $\left[\mathrm{Pt}(\mathrm{ph})\left({ }^{t} \mathrm{Bu}_{3}-\right.\right.$ tpy)]($\left(\mathrm{BF}_{4}\right)$. This observation is consistent with protonation of the $\mathrm{N}$ (piperidyl) groups, which prevents interaction with the metal center. The intensity increase near $380 \mathrm{~nm}$ is likely a consequence of the long-wavelength MLCT band shifting slightly to shorter wavelengths due to the reduced donor properties of the phenyl group.

The room-temperature solution emission spectra of $\left[\mathrm{Pt}\left(\mathrm{pip}_{2} \mathrm{NCN}\right)\left({ }^{t} \mathrm{Bu}_{3} \mathrm{tpy}\right)\right]\left(\mathrm{BF}_{4}\right)$ and $\left[\mathrm{Pt}\left(\mathrm{pip}_{2} \mathrm{NCNH}_{2}\right)\left({ }^{t} \mathrm{Bu}_{3} \mathrm{tpy}\right)\right]\left(\mathrm{PF}_{6}\right)_{3}$ are shown in Fig. 3. $\left[\mathrm{Pt}\left(\mathrm{pip}_{2} \mathrm{NCN}\right)\left({ }^{t} \mathrm{Bu}_{3} \mathrm{tpy}\right)\right]^{+}$is non-emissive, whereas $\left[\mathrm{Pt}\left(\mathrm{pip}_{2} \mathrm{NCNH}_{2}\right)\left({ }^{t} \mathrm{Bu}_{3} \text { tpy }\right)\right]^{3+}$ is weakly emissive or nonemissive. The emission from the protonated adduct is characteristically structured $\left(\lambda_{\max }=470,502,535,585 \mathrm{~nm}\right)$. The significantly diminished intensity of emission from fluid solution samples of $\left[\mathrm{Pt}\left(\mathrm{pip}_{2} \mathrm{NCN}\right)\left({ }^{t} \mathrm{Bu}_{3} \mathrm{tpy}\right)\right]\left(\mathrm{BF}_{4}\right)$ is consistent with the notion that the lowest excited states of platinum(II) terpyridyl complexes are susceptible to quenching by interactions of the metal center with nucleophiles. ${ }^{43}$ The deprotonated piperidyl groups are expected to be strong nucleophiles, and previously studied $\left[\mathrm{Pt}\left(\mathrm{pip}_{2} \mathrm{NCN}\right)(\mathrm{tpy})\right]^{+}$and $\left[\mathrm{Pt}\left(\mathrm{pip}_{2} \mathrm{NCN}\right)(\text { phtpy })\right]^{+}$are also non-emissive. The structured emission profile of $\left[\mathrm{Pt}\left(\mathrm{pip}_{2}-\right.\right.$ $\left.\mathrm{NCNH}_{2}\right)\left({ }^{t} \mathrm{Bu}_{3}\right.$ tpy $\left.)\right]^{3+}$ is similar to those observed for previously reported platinum(II) terpyridyl complexes. ${ }^{34-38}$

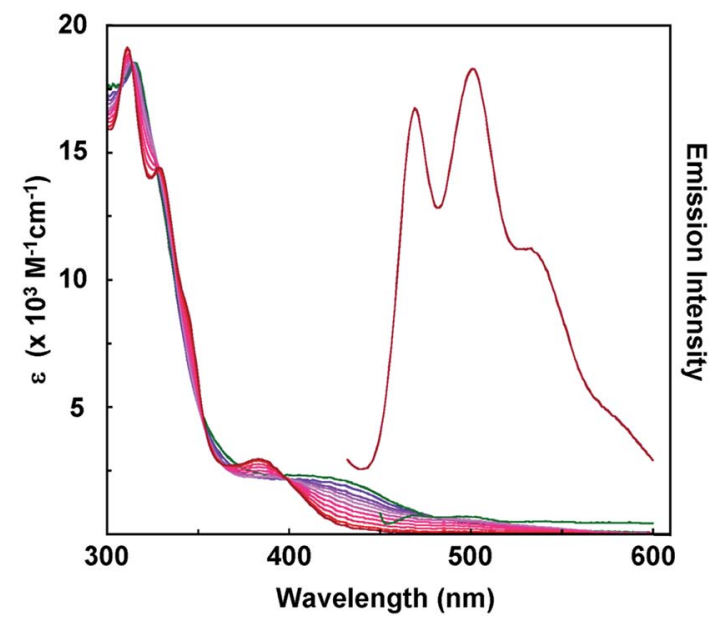

Fig. 3 UV-visible absorption spectra recorded during titration of a $0.12 \mathrm{mM}$ acetonitrile solution of $\left[\mathrm{Pt}\left(\mathrm{pip}_{2} \mathrm{NCN}\right)\left({ }^{t} \mathrm{Bu}_{3} \mathrm{tpy}\right)\right]\left(\mathrm{BF}_{4}\right)(-)$ with 2 equivalents of TFA (triflouroacetic acid, $0.3 \mathrm{M}$ in acetonitrile) in 0.2 equivalents increments. Relative emission spectra of $\left[\mathrm{Pt}\left(\mathrm{pip}_{2}-\right.\right.$ $\left.\mathrm{NCN})\left({ }^{t} \mathrm{Bu}_{3} \mathrm{tpy}\right)\right]\left(\mathrm{BF}_{4}\right)(-)$ and $\left[\mathrm{Pt}\left(\mathrm{pip}_{2} \mathrm{NCNH}_{2}\right)\left({ }^{t} \mathrm{Bu}_{3} \mathrm{tpy}\right)\right]\left(\mathrm{PF}_{6}\right)_{3}(-)$ in acetonitrile. 
The emissions are assigned to predominantly spinforbidden ${ }^{3} \pi-\pi^{*}$ terpyridyl ligand-centered lowest excited states. The vibronic spacings $\left(1200-1500 \mathrm{~cm}^{-1}\right)$ are excited state. $^{31}$ The origin of the emission observed for $\left[\mathrm{Pt}^{2}\left(\mathrm{pip}_{2}-\right.\right.$ $\left.\mathrm{NCNH}_{2}\right)\left({ }^{t} \mathrm{Bu}_{3}\right.$ tpy $\left.)\right]\left(\mathrm{PF}_{6}\right)_{3}$ is only shifted by approximately $2000 \mathrm{~cm}^{-1}$ from the phosphorescence observed for free terpyridine $^{44}$ In addition, the bandshapes and Franck-Condon factors, as indicated by the Huang-Rhys ratios ${ }^{45}\left(I_{1,0} / I_{0,0} \sim 0.85\right)$, are similar to that of the free ligand $\left(I_{1,0} / I_{0,0} \sim 0.85\right)$. Both facts are consistent with the ${ }^{3} \pi-\pi^{*}$ assignment.

\section{Cyclic voltammetry}

Cyclic voltammograms (CVs) of $\left[\mathrm{Pt}(\mathrm{ph})\left({ }^{t} \mathrm{Bu}_{3}\right.\right.$ tpy $\left.)\right]\left(\mathrm{BF}_{4}\right),\left[\mathrm{Pt}\left(\mathrm{pip}_{2}{ }^{-}\right.\right.$ $\mathrm{NCN})\left({ }^{t} \mathrm{Bu}_{3}\right.$ tpy $\left.)\right]\left(\mathrm{BF}_{4}\right), \quad\left[\mathrm{Pt}\left(\mathrm{pip}_{2} \mathrm{NCN}\right)(\right.$ toltpy $\left.)\right]\left(\mathrm{BF}_{4}\right), \quad\left[\mathrm{Pt}\left(\mathrm{NO}_{2}-\mathrm{pip}_{2}-\right.\right.$ $\mathrm{NCN})($ tpy $)]\left(\mathrm{BF}_{4}\right)$, and $\left[\mathrm{Pt}\left(\mathrm{MeO}-\mathrm{pip}_{2} \mathrm{NCN}\right)(\mathrm{tpy})\right]\left(\mathrm{BF}_{4}\right)$ in $0.1 \mathrm{M}$ TBAPF $_{6}$ acetonitrile are shown in Fig. 4 and 5 . The $\mathrm{CV}$ of $\left[\mathrm{Pt}\left(\mathrm{pip}_{2} \mathrm{NCN}\right)(\mathrm{tpy})\right]\left(\mathrm{BF}_{4}\right)$ in $0.1 \mathrm{M} \mathrm{TBAPF}_{6}$ acetonitrile is shown in Fig. 5 for comparison. Cyclic voltammetry data are summarized in Table 1.

The CVs of each complex in acetonitrile solution $(0.1 \mathrm{M}$ $\mathrm{TBAPF}_{6}, 0.1 \mathrm{~V} \mathrm{~s}^{-1}$ ) exhibit two reversible one-electron reduction waves near $-1.0 \mathrm{~V}\left(E^{\circ}\right)$ and $-1.5 \mathrm{~V}\left(E^{\circ}\right)$, with peak-to-peak separations $\left(\Delta E_{\mathrm{p}}\right)$ of $62 \pm 8$ and $61 \pm 8 \mathrm{mV}$, respectively. Assignment of the observed redox processes can be inferred from comparison to the electrochemical behavior of a series of related compounds. Under identical conditions, neither free tpy, $\mathrm{pip}_{2} \mathrm{NCNBr}$ nor $\mathrm{Pt}\left(\mathrm{pip}_{2} \mathrm{NCN}\right) \mathrm{Cl}$ is reduced at potentials larger than $-2.10 \mathrm{~V}$, suggesting that the one-electron reduction processes are associated with the $\mathrm{Pt}(\mathrm{tpy})$ unit. $\mathrm{Pt}(\mathrm{tpy}) \mathrm{Cl}^{+}$has been reported to undergo reversible one-electron reductions in

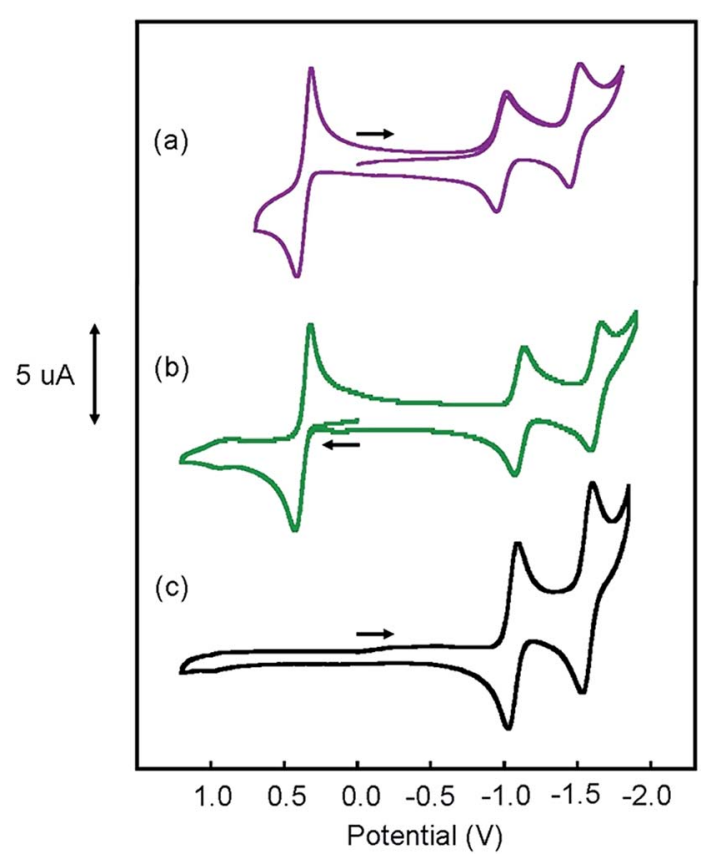

Fig. 4 Cyclic voltammograms of $1 \mathrm{mM}$ (a) $\left[\mathrm{Pt}\left(\mathrm{pip}_{2} \mathrm{NCN}\right)(\right.$ toltpy)](BF 4$)$

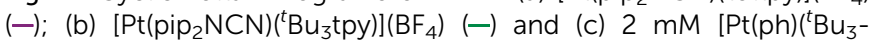
tpy)] $\left(\mathrm{BF}_{4}\right)(-)$ in acetonitrile (0.1 $\mathrm{M} \mathrm{TBAPF}_{6}$, gold working electrode, $0.25 \mathrm{~V} \mathrm{~s}^{-1}$ ).

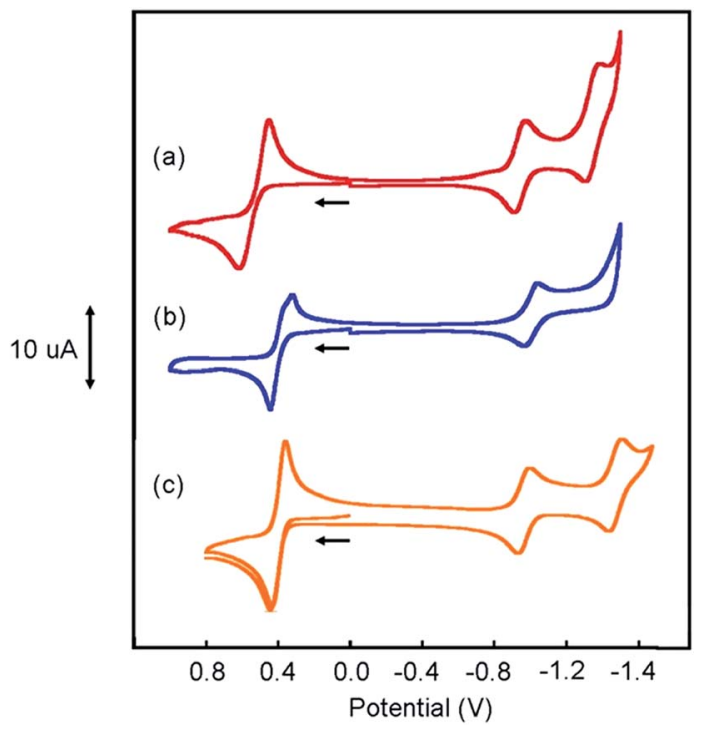

Fig. 5 Cyclic voltammograms of (a) $2 \mathrm{mM} \quad\left[\mathrm{Pt}\left(\mathrm{NO}_{2}-\mathrm{pip}_{2}-\right.\right.$ $\mathrm{NCN})(\mathrm{tpy})]\left(\mathrm{BF}_{4}\right)(-)$, (b) $2 \mathrm{mM}\left[\mathrm{Pt}\left(\mathrm{MeO}-\mathrm{pip}_{2} \mathrm{NCN}\right)(\mathrm{tpy})\right] \mathrm{OTf}(-)$ and (c) $\left[\mathrm{Pt}\left(\mathrm{pip}_{2} \mathrm{NCN}\right)(\mathrm{tpy})\right]\left(\mathrm{BF}_{4}\right)(-)$ in $0.1 \mathrm{M}^{\mathrm{TBAPF}} 6 \mathrm{CH}_{3} \mathrm{CN}$ (gold working electrode, $0.1 \mathrm{~V} \mathrm{~s}^{-1}$ ).

$\operatorname{DMF}\left(0.1 \mathrm{M} \mathrm{TBAPF}_{6}\right)$ at $E^{\circ \prime}=-0.74$ and $E^{\circ \prime}=-1.30 \mathrm{~V} v s . \mathrm{Ag} /$ $\mathrm{AgCl}$ whereas $\mathrm{Zn}$ (tpy) $\mathrm{Cl}_{2}$ undergoes reversible one-electron reduction at $E^{\circ \prime}=-1.36 \mathrm{~V}^{46}$ The cathodic shift of the ligandcentered couples in platinum(II) complexes is attributed to stabilization of the reduced tpy ligand as a result of coupling between the empty $6 \mathrm{p}_{z}(\mathrm{Pt})$ and the $\pi^{*}(\mathrm{tpy})$ orbitals. ${ }^{46}$ As observed for $\left[\mathrm{Pt}\left(\mathrm{Z}\right.\right.$-pip $\left.{ }_{2} \mathrm{NCN}\right)(\mathrm{R} \text {-tpy) }]^{+}$complexes, the fact that $[\mathrm{Pt}(\mathrm{ph})(\mathrm{tpy})]^{+}$and similar complexes without the piperidyl groups such as $\left[\mathrm{Pt}(2,6-\text { dimethylphenyl)(tpy) }]^{+}\left(E^{\circ \prime}=-0.96 \mathrm{~V}\right.\right.$, $\Delta E_{\mathrm{p}}=60 \mathrm{mV}, i_{\mathrm{pc}} / i_{\mathrm{pa}}=0.91 ; E^{\circ \prime}=-1.49 \mathrm{~V}, \Delta E_{\mathrm{p}}=64 \mathrm{mV}, i_{\mathrm{pc}} / i_{\mathrm{pa}}=$ $0.90)^{27}$ in acetonitrile solutions also undergo two reversible oneelectron reductions support this assignment.

The $\mathrm{Z}$ and $\mathrm{R}$ substituents influence the apparent potentials of both cathodic processes. The $\mathrm{NO}_{2}$ substituent that anodically shifts the reductions, waves by $0.1 \mathrm{~V}$ and $0.23 \mathrm{~V}$, respectively (Fig. 5). The tolyl terpyridyl substituent shifts only the second reduction anodically by $0.02 \mathrm{~V}$ (Fig. 4). On the other hand, the $\mathrm{pip}_{2} \mathrm{NCN}^{-} \mathrm{MeO}$ and $t$-butyl terpyridyl substituents act as electron donating groups and shift both reductions cathodically by $0.02 \mathrm{~V}$ and $0.13 \mathrm{~V}$ from those of $\mathrm{Pt}\left(\mathrm{pip}_{2} \mathrm{NCN}\right)(\mathrm{tpy})^{+}$, respectively (Fig. 4 and 5). Similar shifts ( $-0.11 \mathrm{~V}$ and $-0.14 \mathrm{~V}$, respectively) have been observed for the introduction of $t$-butyl substituent in $\mathrm{Pt}\left(\mathrm{R}\right.$-tpy) $\mathrm{C} \equiv \mathrm{C}-$ phenyl-C$\equiv \mathrm{C}-\mathrm{Re}\left(\mathrm{N}^{\wedge} \mathrm{N}\right)(\mathrm{CO})_{3}\left(\right.$ tpy, $E_{1 / 2}^{\text {red }}:-0.90 \mathrm{~V}$, $-1.37 \mathrm{~V} ;{ }^{t} \mathrm{Bu}_{3}$ tpy, $E_{1 / 2}^{\text {red }}:-1.01 \mathrm{~V},-1.51 \mathrm{~V}$, in $0.1 \mathrm{M} \mathrm{TBAPF}_{6}$ acetonitrile solution, vs. SCE, glassy carbon working electrode) ${ }^{47}$ However, for $\mathrm{Pt}($ tpy $)\left(\mathrm{C} \equiv \mathrm{C}-\mathrm{C}_{6} \mathrm{H}_{5}-\mathrm{Z}\right)^{+}$complexes, introduction of either $\mathrm{NO}_{2}$ or $\mathrm{MeO}$ substituents shift the first reduction process to more negative potentials (by $-0.21 \mathrm{~V}$ and $-0.08 \mathrm{~V}$, respectively) while not influencing the second reduction process $\left(\mathrm{Pt}\right.$ (tpy) $\left(\mathrm{C} \equiv \mathrm{C}-\mathrm{C}_{6} \mathrm{H}_{5}\right)^{+}, E_{1 / 2}^{\mathrm{red}}=-0.97 \mathrm{~V},-1.46 \mathrm{~V}$, in $0.1 \mathrm{M}$ TBAH acetonitrile, $v s$. SCE, glassy carbon working electrode).$^{48}$ Apparently, the nature of the fourth ligand carrying the substituent influences the way the substituent effect $\mathrm{Pt}(\mathrm{tpy})$ reductions. 
Table 1 Cyclic voltammetry data for $\left[\mathrm{Pt}(\mathrm{Ph})\left({ }^{\left.\mathrm{t} B \mathrm{Bu}_{3} \mathrm{tpy}\right)}\right]^{+}\right.$and $\left[\mathrm{Pt}\left(\mathrm{Z}-\mathrm{pip}_{2} \mathrm{NCN}\right)(\mathrm{R} \text {-tpy) }]^{+}\right.$complexes in acetonitrile $(0.1 \mathrm{M}$ TBAPF 6 , gold working electrode, $0.1 \mathrm{Vs}^{-1}$ )

\begin{tabular}{|c|c|c|}
\hline Compound & $E_{\mathrm{ox}}^{\circ \prime}(\mathrm{V})\left(\Delta E_{\mathrm{p}}(\mathrm{mV})\right)$ & $E_{\mathrm{red}}^{\circ \prime}(\mathrm{V})\left(\Delta E_{\mathrm{p}}(\mathrm{mV})\right)$ \\
\hline$\left[\mathrm{Pt}(\mathrm{Ph})\left({ }^{t} \mathrm{Bu}_{3} \mathrm{tpy}\right)\right]^{+}$ & - & $-1.06(62),-1.57(69)$ \\
\hline$\left[\mathrm{Pt}\left(\mathrm{pip}_{2} \mathrm{NCN}\right)\left({ }^{t} \mathrm{Bu}_{3} \mathrm{tpy}\right)\right]^{+}$ & $0.36(68)$ & $-1.11(54),-1.62(58)$ \\
\hline$\left[\mathrm{Pt}\left(\mathrm{NO}_{2}-\mathrm{pip}_{2} \mathrm{NCN}\right)(\mathrm{tpy})\right]^{+}$ & $0.62(89)$ & $-0.88(61),-1.33(53)$ \\
\hline$\left[\mathrm{Pt}\left(\mathrm{MeO}-\mathrm{pip}_{2} \mathrm{NCN}\right)(\mathrm{tpy})\right]^{+}$ & $0.37(102)$ & $-1.00(70),-1.52(67)$ \\
\hline$\left[\mathrm{Pt}\left(\mathrm{pip}_{2} \mathrm{NCN}\right)(\mathrm{tpy})\right]^{+}$ & $0.40(54)$ & $-0.98(65),-1.50(61)($ ref. 4$)$ \\
\hline
\end{tabular}

$\mathrm{Pt}(\mathrm{ph})\left({ }^{t} \mathrm{Bu}_{3} \mathrm{tpy}\right)^{+}$is not oxidized at $<1.2 \mathrm{~V}$ vs. $\mathrm{Ag} / \mathrm{AgCl}$. By contrast, each of the platinum(II) complexes with both a Z$\operatorname{pip}_{2} \mathrm{NCN}^{-}$and a terpyridyl ligand undergo a two-electron oxidation process in the $0.4-0.6 \mathrm{~V}$ range $\left(E^{\circ \prime}\right)$, as previously noted for $\left[\mathrm{Pt}\left(\mathrm{pip}_{2} \mathrm{NCN}\right)(\mathrm{tpy})\right]^{+}\left(E^{\circ \prime}=0.40 \mathrm{~V}, \Delta E_{\mathrm{p}}=74 \mathrm{mV}, 0.25 \mathrm{~V}\right.$ $\left.\mathrm{s}^{-1}\right),{ }^{4} \quad\left[\mathrm{Pt}\left(\mathrm{pip}_{2} \mathrm{NCN}\right)\left({ }^{t} \mathrm{Bu}_{3} \text { tpy }\right)\right]^{+}$and $\left[\mathrm{Pt}\left(\mathrm{pip}_{2} \mathrm{NCN}\right)(\text { toltpy })\right]^{+}$ undergo a chemically reversible and nearly electrochemically reversible two-electron oxidation processes at $E^{\circ \prime}=0.36 \mathrm{~V}\left(i_{\mathrm{pc}}\right)$ $\left.i_{\mathrm{pa}}=1.02, \Delta E_{\mathrm{p}}=68 \mathrm{mV}, 0.1 \mathrm{~V} \mathrm{~s}^{-1}\right)$ and $E^{\circ \prime}=0.37 \mathrm{~V}\left(i_{\mathrm{pc}} / i_{\mathrm{pa}}=1.1\right.$, $\left.\Delta E_{\mathrm{p}}=94 \mathrm{mV}, 0.25 \mathrm{~V} \mathrm{~s}^{-1}\right)$, respectively. For $\left[\mathrm{Pt}\left(\mathrm{NO}_{2}-\mathrm{pip}_{2^{-}}\right.\right.$ $\mathrm{NCN})(\text { tpy) }]^{+}$and $\left[\mathrm{Pt}\left(\mathrm{MeO}-\mathrm{pip}_{2} \mathrm{NCN}\right)(\mathrm{tpy})\right]^{+}$, the oxidation process occurs at $E^{\circ \prime}=0.62 \mathrm{~V}\left(i_{\mathrm{pc}} / i_{\mathrm{pa}}=1.33, \Delta E_{\mathrm{p}}=89 \mathrm{mV}, 0.1 \mathrm{~V} \mathrm{~s}^{-1}\right)$ and $E^{\circ \prime}=0.37 \mathrm{~V}\left(i_{\mathrm{pc}} / i_{\mathrm{pa}}=0.97, \Delta E_{\mathrm{p}}=102 \mathrm{mV}, 0.1 \mathrm{~V} \mathrm{~s}^{-1}\right)$, respectively. No splitting of any of the waves was observed over the range of investigated scan rates. As assessed by the anodiccathodic peak-to-peak separation $\left(\Delta E_{\mathrm{p}}\right)$ at a given sweep rate, the electrochemical reversibility varies among the five twoelectron reagents $\left(\Delta E_{\mathrm{p}}, 50-100 \mathrm{mV}, 0.1 \mathrm{~V} \mathrm{~s}^{-1}\right)$. The reversibility does not vary with electron-donor properties of the substituents in an obvious manner; however it appears that the presence of the $\mathrm{Z}$ substituents on the $\operatorname{pip}_{2} \mathrm{NCN}^{-}$ligand tends to slow the electron-transfer kinetics. The reversibility of the $\mathrm{Ru}(\mathrm{II}) /$ $\mathrm{Ru}(\mathrm{III})$ process for a library of ruthenium terpyridyl complexes also varies somewhat irratically. ${ }^{28,49}$ Nazeeruddin et al. have reported diminished reversibility for ruthenium bipyridyl complexes with multiple strong electron donor substituents such as $\mathrm{NMe}_{2} \cdot{ }^{50}$ In the present case, it appears that $\Delta E_{\mathrm{p}}$ tracks with the severity of electrode passivation problems as indicated by the shift in $E_{\mathrm{pa}}$ and loss of current with consecutive sweeps. For all five complexes, the ratios of the peak anodic current of the oxidation process to the peak cathodic current of the first reduction wave are between 2.0 and 2.3.

Although the $i_{\mathrm{pa}} / i_{\mathrm{pc}}$ are less than the predicted value for a Nernstian two-electron process $\left(2.8\left(=2^{3 / 2}\right)\right)$, the ratios clearly exceed the expected value of 1.0 for a one-electron process. The $\Delta E_{\mathrm{p}}$ for a diffusion controlled two-electron Nernstian process is expected to be $29.5 \mathrm{mV} .^{51}$ In fact, at $0.1 \mathrm{~V} \mathrm{~s}^{-1}$ the couples are clearly not electrochemically reversible as indicated by the relatively large values of $\Delta E_{\mathrm{p}}$, and therefore the values of $i_{\mathrm{pa}} / i_{\mathrm{pc}}$ cannot be expected to approach the Nernstian limits. Since the oxidations clearly involve transfer of considerably more charge than observed for the reduction, the processes are attributed to a net two-electron oxidation of the complexes.

The apparent two-electron oxidation waves observed for $\left[\mathrm{Pt}\left(\mathrm{Z}-\mathrm{pip}_{2} \mathrm{NCN}\right)(\mathrm{R}-\mathrm{tpy})\right]^{+}$complexes are absent in cyclic voltammograms of related compounds. For example, neither $\mathrm{Pt}$ (tpy)(dmph)+, $\operatorname{pip}_{2} \mathrm{NCNBr}$ nor $\operatorname{pip}_{2} \mathrm{NCNBrH}_{2}{ }^{2+}$ is oxidized at potentials $<1.2 \mathrm{~V},{ }^{4}$ and $\mathrm{Pt}\left(\mathrm{pip}_{2} \mathrm{NCN}\right) \mathrm{Cl}$ undergoes irreversible metal-centered oxidation near $0.8 \mathrm{~V}^{39}$ Taken together, these data indicate that both the $\operatorname{pip}_{2} \mathrm{NCN}^{-}$and terpyridyl ligands play important roles in the unusual redox chemistry of $\mathrm{Pt}(\mathrm{Z}$ pip $\left._{2} \mathrm{NCN}\right)\left(\mathrm{R}\right.$-tpy) ${ }^{+}$complexes. The availability of the amine lone electron pairs is critical to facilitating reversible two-electron oxidation and stabilizing the resulting $\mathrm{Pt}(\mathrm{Iv})$ center. For example, protonation of the piperidyl groups (e.g., $\mathrm{Pt}\left(\mathrm{pip}_{2}\right.$ $\left.\left.\mathrm{NCNH}_{2}\right)(\mathrm{tpy})^{3+}\right),{ }^{4}$ results in irreversible oxidation near $0.4 \mathrm{~V}$ accompanied by electrode fouling.

In order to further characterize the electrochemical behavior of these systems, CVs of $\mathrm{Pt}\left(\mathrm{pip}_{2} \mathrm{NCN}\right)\left({ }^{t} \mathrm{Bu}_{3} \mathrm{tpy}\right)^{+}$were recorded for the first reduction process $(-0.8$ to $-1.3 \mathrm{~V})$ and the oxidation process $(0.2$ to $0.6 \mathrm{~V})$ over a range of scan rates from 0.01 to $25 \mathrm{~V}$ $\mathrm{s}^{-1}$ (Fig. 6). $\Delta E_{\mathrm{p}}$ of the first reduction $\left(E^{\circ \prime}=-1.11 \mathrm{~V}\right)$ is essentially invariant $(59 \pm 6 \mathrm{mV}$ ) for scan rates ranging from 0.01 to $25 \mathrm{~V} \mathrm{~s}^{-1}$. The cathodic peak current $\left(i_{\mathrm{pc}}\right)$ exhibits an approximately linear dependence on the square root of the scan rate $\left(\nu^{1 /}\right.$ ${ }^{2}$ ), as predicted by the Randles-Ševčik equation for Nernstian conditions. $^{52-54}$

$$
i_{\mathrm{p}}=2.69 \times 10^{5} n^{3 / 2} A D^{1 / 2} C \nu^{1 / 2}
$$

where $n=$ electron stoichiometry, $A=$ electrode area, $D=$ diffusion coefficient, and $C=$ concentration. For the oxidation process, $\Delta E_{\mathrm{p}}$ increases continuously from 43 to $103 \mathrm{mV}$ as the scan rate is increased from 0.01 to $1.5 \mathrm{~V} \mathrm{~s}^{-1}$. With decreasing scan rate, $\Delta E_{\mathrm{p}}$ approaches the two-electron Nernstian limit of 29.5 (ref. 51 and 55) with $i_{\mathrm{pc}} / i_{\mathrm{pa}}=1.08$ at $0.01 \mathrm{~V} \mathrm{~s}^{-1}$. The behavior of the other complexes is qualitatively similar, $\Delta E_{\mathrm{p}}$ increases with scan rate. The dependence of $\Delta E_{\mathrm{p}}$ on the scan rate is consistent with a large structural reorganization resulting in slow reaction kinetics.

In order to verify the electron stoichiometry of the oxidation process for $\left[\mathrm{Pt}\left(\mathrm{pip}_{2} \mathrm{NCN}\right)\left({ }^{t} \mathrm{Bu}_{3} \mathrm{tpy}\right)\right]\left(\mathrm{BF}_{4}\right)$, the anodic peak current $\left(i_{\mathrm{pa}}\right)$ is plotted against $\nu^{1 / 2}$ in Fig. 6 . The data are remarkably linear over the entire range of scan rates $\left(0.01\right.$ to $\left.30 \mathrm{~V} \mathrm{~s}^{-1}\right)$ as predicted by the Randles-Ševčik eqn (1). The ratio (2.40) of the slope of the best fit line to that obtained for the first reduction process is used to derive an estimate of $n_{\text {ox }} / n_{\text {red }}(=1.8)$. Since the reduction is known to be a one electron process, $n_{\mathrm{ox}}=1.8$ is consistent with an oxidation that involves two-electron transfer per Pt center. See more detailed explanation in the ESI. $\dagger$ 


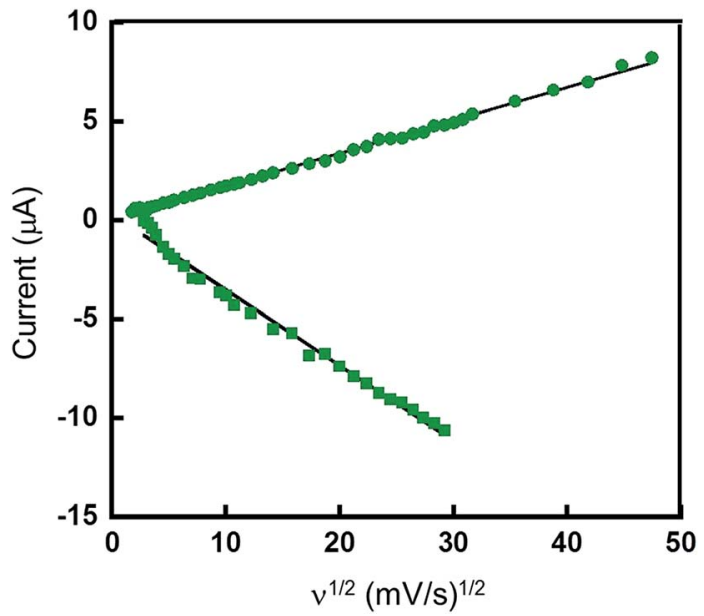

Fig. 6 Dependence of anodic peak current $\left(i_{\mathrm{pa}}\right)$ for $0.36 \mathrm{~V}$ oxidation process $(\square)$ and cathodic peak current $\left(i_{\mathrm{pc}}\right)$ for $-1.11 \mathrm{~V}$ reduction process ( $\bullet$ ) on the square root of the scan rate $\left(\nu^{1 / 2}\right)$ for $1 \mathrm{mM}$ $\left[\mathrm{Pt}\left(\mathrm{pip}_{2} \mathrm{NCN}\right)\left({ }^{t} \mathrm{Bu}_{3} \mathrm{tpy}\right)\right]\left(\mathrm{BF}_{4}\right)$ in acetonitrile (0.1 M TBAPF 6 ). Scans recorded from 0.2 to $0.6 \mathrm{~V}$ and from -1.2 to $-1.7 \mathrm{~V}$. The lines represent linear fits of the anodic and cathodic currents.

The substituents on the $\operatorname{pip}_{2} \mathrm{NCN}^{-}$and tpy ligands significantly influence the apparent $\mathrm{Pt}(\mathrm{IV} / \mathrm{II})$ redox couple, $E^{\circ \prime}$, the influence of the $\mathrm{R}_{n}$ substituents is comparatively small. For example, $E^{\circ}$ is cathodically shifted by 0.04 and 0.03 volts in $\left[\mathrm{Pt}\left(\mathrm{pip}_{2} \mathrm{NCN}\right)\left({ }^{t} \mathrm{Bu}_{3} \text { tpy }\right)\right]^{+}$and $\left[\mathrm{Pt}\left(\mathrm{pip}_{2} \mathrm{NCN}\right)(\text { toltpy })\right]^{+}$, respectively. A comparable cathodic shift $(0.05 \mathrm{~V})$ has been observed for the irreversible $\mathrm{Pt}(\mathrm{II}) / \mathrm{Pt}(\mathrm{III})$ process when tpy is replaced by ${ }^{t} \mathrm{Bu}_{3}$ tpy in $\mathrm{Pt}$ (R-tpy) $\mathrm{C} \equiv \mathrm{C}-$ phenyl- $\mathrm{C} \equiv \mathrm{C}-\mathrm{Re}\left(\mathrm{N}^{\wedge} \mathrm{N}\right)(\mathrm{CO})_{3}$ complexes $\left(\mathrm{N}^{\wedge} \mathrm{N}\right.$ $=4,4^{\prime}$-bis-t-butylbipyridine; $\mathrm{R}=\mathrm{H}$ (tpy), $E_{\mathrm{pa}}=1.41 \mathrm{~V} ; \mathrm{R}=t$-butyl ( ${ }^{t} \mathrm{Bu}_{3}$ tpy), $E_{\mathrm{pa}}=1.36 \mathrm{~V}$; in $0.1 \mathrm{M} \mathrm{TBAPF}_{6}$ acetonitrile solution, $v s$. SCE, glassy carbon working electrode).$^{47}$ Similarly, replacing tpy ligands with phenyl-tpy in $\mathrm{Ru}(\mathrm{tpy})_{2}{ }^{2+}$ causes a cathodic shift of 0.02 volts $\left(\mathrm{Ru}(\text { tpy })_{2}{ }^{2+}, E^{\circ \prime}=0.92 \mathrm{~V} ; \mathrm{Ru}(\text { ph-tpy })_{2}{ }^{2+}, E^{\circ \prime}=0.90 \mathrm{~V}\right.$; in acetonitrile, $\left.v s . \mathrm{Fc} / \mathrm{Fc}^{+}\right) \cdot{ }^{49}$

The $\mathrm{Z}$ substituents have a more substantial influence on the apparent redox potential. For $\mathrm{Pt}\left(\mathrm{NO}_{2}-\mathrm{pip}_{2} \mathrm{NCN}\right)(\mathrm{tpy})^{+}, E^{\mathrm{ol}}(0.62$ $\mathrm{V})$ is anodically shifted by $0.22 \mathrm{~V}$ from the two-electron oxida-

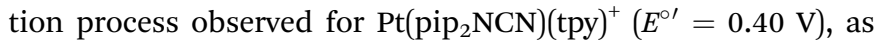
expected for a more electron-poor metal center. The involvement of the metal-center is confirmed by comparison to the redox chemistry of ruthenium(III/II) polypyridyl complexes. Previously, Nazeeruddin et al. have shown that there exists an approximate linear correlation between the ruthenium(III/II) redox potentials of $\mathrm{Ru}\left(\mathrm{Z}, \mathrm{Z}^{\prime}-\mathrm{bpy}\right)_{x}(\mathrm{bpy})_{3-x}{ }^{2+}$ complexes and the Hammett parameters of the bipyridyl substituents. ${ }^{50}$ Fig. 7 shows the dependence of $E^{\circ \prime}$ on the effective Hammett parameter $\sum \sigma_{\mathrm{p}}{ }^{+}$, which derives from summing the $\sigma_{\mathrm{p}}{ }^{+}$values for each of the substituents of the six pyridyl groups. The use of ${\sigma_{\mathrm{p}}}^{+}$is rationalized on grounds that it is a more suitable descriptor for a reaction that involves increasing positive charge on the metal center. We have applied this analysis to the five Pt(Z-pip $2^{-}$ $\mathrm{NCN})\left(\right.$ tpy) ${ }^{+}$two-electron reagents, where ${\sigma_{\mathrm{p}}}^{+}$values are summed for the three substituents of the terpyridyl ligand and the single substituent of the $\operatorname{pip}_{2} \mathrm{NCN}^{-}$ligand. The analysis reveals a similar approximate linear relationship, albeit over a more narrow range of $\sum \sigma_{\mathrm{p}}{ }^{+}$(Fig. 7).

For both $\mathrm{Pt}(\mathrm{II})$ and $\mathrm{Ru}(\mathrm{II})$ complexes, the observed $E^{\circ}$ reveal, as expected, that the oxidation of the metal center becomes more difficult as the electron withdrawing character of the substituents increases. The relative slopes of best-fit lines $E^{\prime \prime}$ versus $\sum \sigma_{\mathrm{p}}{ }^{+}(\mathrm{Ru}, 0.13 \mathrm{~V} ; \mathrm{Pt}, 0.11 \mathrm{~V})$ reflect the fact that replacement of a $\mathrm{MeO}$ group with $\mathrm{NO}_{2}$ causes a slightly greater anodic shift in $E^{\circ}$ for the two-electron platinum reagents $(0.25$ $\mathrm{V})$ than for the $\mathrm{Ru}\left(4,4^{\prime}-\mathrm{R}_{2} \mathrm{bpy}\right)(\mathrm{bpy})_{2}{ }^{2+}\left(0.18 \mathrm{~V}\right.$ per $\mathrm{MeO} / \mathrm{NO}_{2}$ substitution). Potentials for $\mathrm{Ru}(\mathrm{R} \text {-tpy })_{2}{ }^{2+}$ also would seem to suggest a more shallow dependence on $\mathrm{EtO} / \mathrm{NO}_{2}$ substitution $(0.19 \mathrm{~V}),{ }^{29,49}$ however, for this limited data set, we regard the slopes of the best-fit lines in Fig. 7 as essentially identical within the scatter of the data. The general agreement between these data sets confirms that the two-electron process is metalcentered and suggests that, over this narrow range of potentials, the $\mathrm{d}^{6} / \mathrm{d}^{7}$-electron and $\mathrm{d}^{7} / \mathrm{d}^{8}$-electron couples are comparably affected by changes in ligand substituents.

Interestingly, in the cases of $\mathrm{Ru}(\mathrm{R} \text {-tpy })_{2}{ }^{2+}$ and $\mathrm{Ru}\left(4,4^{\prime}-\mathrm{R}_{2}\right.$ bpy)(bpy) ${ }_{2}{ }^{2+}$ complexes, the nitro and ethoxy substituents each strongly shift the redox couple from that of the unsubstituted complex $\left(\mathrm{Ru}\left(\mathrm{NO}_{2} \text {-tpy }\right)_{2}{ }^{2+}, 1.114 \mathrm{~V} ; \mathrm{Ru}(\mathrm{tpy})_{2}{ }^{2+}, 0.92 \mathrm{~V} ; \mathrm{Ru}(\mathrm{OEt}-\right.$ tpy $)_{2}{ }^{2+}, 0.74 \mathrm{~V}$, in acetonitrile $v s . \quad \mathrm{Fc} / \mathrm{Fc}^{+} ;{ }^{+43,49} \mathrm{Ru}\left(4,4^{\prime}-\left(\mathrm{NO}_{2}\right)_{2^{-}}\right.$ bpy)(bpy $)_{2}{ }^{2+}, 1.48 \mathrm{~V} ; \mathrm{Ru}(\mathrm{bpy})_{3}{ }^{2+}, 1.26 \mathrm{~V} ; \mathrm{Ru}\left(4,4^{\prime}-(\mathrm{MeO})_{2^{-}}\right.$ bpy)(bpy) ${ }_{2}{ }^{2+}, 1.05 \mathrm{~V}$, in acetonitrile $v s$. SCE). ${ }^{50}$ The potential shifts per substituent upon by replacing $\mathrm{H}$ with $\mathrm{MeO}$ or with $\mathrm{NO}_{2}$ are comparable $\left(\mathrm{Ru}(\mathrm{R} \text {-tpy })_{2}{ }^{2+}, \mathrm{R}=\mathrm{NO}_{2}, 0.97 \mathrm{~V} ; \mathrm{R}=\mathrm{EtO}\right.$, $-0.09 \mathrm{~V} ;{ }^{29,49} \mathrm{Ru}\left(4,4^{\prime}-\mathrm{R}_{2}\right.$ bpy)(bpy) ${ }_{2}{ }^{2+}, \mathrm{R}=\mathrm{NO}_{2}, 0.098 \mathrm{~V} ; \mathrm{R}=\mathrm{MeO}$, $-0.075 \mathrm{~V}){ }^{50,56}$ By contrast in the $\left[\mathrm{Pt}\left(\mathrm{Z}-\mathrm{pip}_{2} \mathrm{NCN}\right)(\mathrm{tpy})\right]^{+}$series, the nitro group has a much stronger influence $(+0.22 \mathrm{~V})$ on the apparent redox couple than the methoxy substituent $(-0.03 \mathrm{~V})$.

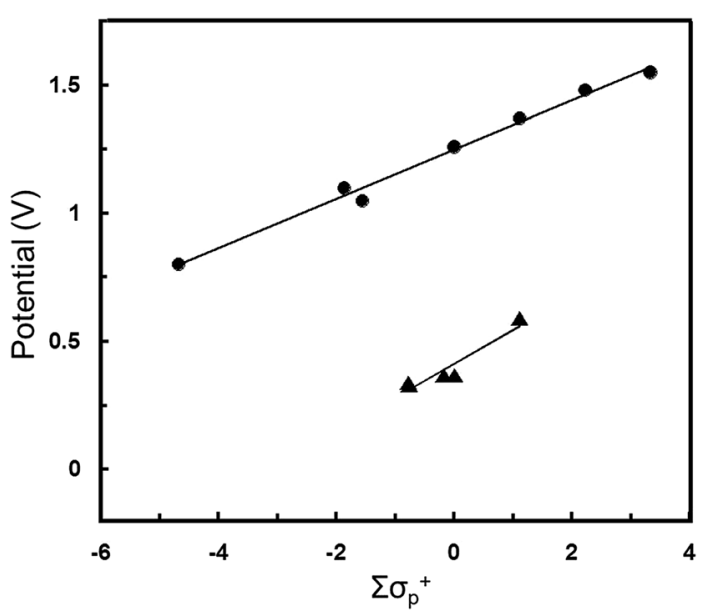

Fig. 7 Correlation of oxidation potential ( $E^{\circ \prime}$ vs. SCE) to Hammett parameter $\sum \sigma^{+}$. $\Delta$ represents $\mathrm{Pt}\left(\mathrm{Z}-\mathrm{pip}_{2} \mathrm{NCN}\right)(\mathrm{R}$-tpy)+ complexes where $\mathrm{Z}=\mathrm{NO}_{2}, \mathrm{MeO}, \mathrm{H}$ and $\mathrm{R}=\mathrm{H}, t$-butyl, phenyl, $E^{\circ \prime}=0.13 \sum \sigma \mathrm{p}^{+}+$ $0.41(R=0.952)$. represents $\mathrm{Ru}\left(\mathrm{Z}, \mathrm{Z}^{\prime}-\mathrm{bpy}\right)_{x}(\mathrm{bpy})_{3-x}{ }^{2+}$ complexes $^{50}$ where $\mathrm{Z}=\mathrm{NO}_{2}, \mathrm{H}, \mathrm{Me}, \mathrm{MeO},(x=0,1,2,3), E^{\circ \prime}=0.10 \sum \sigma \mathrm{p}^{+}+1.25(R=$ 0.995). $\sum \sigma p^{+}$is calculated by summing the $\sigma p^{+}$values for each substituent; a 6 coordinate $\mathrm{Ru}\left(\mathrm{Z}, \mathrm{Z}^{\prime}-\mathrm{bpy}\right)_{x}(\mathrm{bpy})_{3-x}{ }^{2+}$ complex has six different substituents, whereas a $\mathrm{Pt}\left(\mathrm{Z}-\mathrm{pip}_{2} \mathrm{NCN}\right)(\mathrm{R}-\mathrm{tpy})^{+}$complex has four substituents. 
A similar effect is observed for $\mathrm{Pt}(\mathrm{tpy})\left(\mathrm{C} \equiv \mathrm{C}-\mathrm{C}_{6} \mathrm{H}_{5}-\mathrm{Z}\right)^{+}(\mathrm{Z}=$ $\left.\mathrm{NO}_{2}, \mathrm{MeO}, \mathrm{H}\right)$ complexes where the $\mathrm{NO}_{2}$ substituent is proposed to cause the irreversible one electron $\mathrm{Pt}(\mathrm{II}) / \mathrm{Pt}(\mathrm{III})$ oxidation potential to shift anodically by 0.24 volts from that of $\mathrm{Pt}(\mathrm{tpy})\left(\mathrm{C} \equiv \mathrm{C}_{-} \mathrm{C}_{6} \mathrm{H}_{5}\right)^{+}\left(E_{\mathrm{pa}}=1.22 \mathrm{~V}\right.$, in $0.1 \mathrm{M}$ TBAH acetonitrile solution, vs. SCE, glassy carbon working electrode); however, in that case the influence of the OMe substituent also is substantial $(-0.22 \mathrm{~V})$, and it is not clear that these shifts represent thermodynamic potentials. ${ }^{48}$ In the case of the $\mathrm{Ru}(\mathrm{III} / \mathrm{II})$ systems, the redox process involves a $\mathrm{d} \pi$ orbital, whereas the oxidation of platinum(II) formally involves a $\mathrm{d}_{z^{2}}$ orbital. On the other hand, the Hammett inductive $\left(\sigma_{\mathrm{I}}\right)$ and mesomeric $\left(\sigma_{\mathrm{m}}\right)$ constants for nitro $(0.7,0)$ and methoxy $(0.31,-0.41)$ groups suggest significant differences in the coupling of substituent electron-donor properties. Therefore, the comparative insensitivity of the platinum system to the methoxy substituent is consistent with the influence of resonance on the $\mathrm{d}_{z^{2}}$ level being significantly less compared to its influence on the $\mathrm{d} \pi$ levels of ruthenium(III/ II) polypyridyl complexes. Similarly, the increased sensitivity to nitro substituent suggests that the influence of induction on the $\mathrm{d}_{z^{2}}$ level is significantly increased.

\section{Conclusions}

Substituted $\mathrm{pip}_{2} \mathrm{NCN}^{-}$ligands, their $\mathrm{Pt}(\mathrm{II})$ halide complexes, and novel $\left[\mathrm{Pt}\left(\mathrm{Z}-\right.\right.$ pip $\left._{2} \mathrm{NCN}\right)(\mathrm{R} \text {-tpy) }]^{+}$complexes with $\mathrm{Z}=\mathrm{NO}_{2}$, $\mathrm{MeO}, \mathrm{H}$ and $\mathrm{R}=\mathrm{H}$, tertyl butyl, tolyl substituents have been prepared. For $\left[\mathrm{Pt}\left(\mathrm{Z}-\mathrm{pip}_{2} \mathrm{NCN}\right)(\mathrm{R} \text {-tpy) }]^{+},{ }^{1} \mathrm{H}\right.$ NMR spectroscopy shows that the Z-pip ${ }_{2} \mathrm{NCN}^{-}$ligand is bonded monodentate whereas the R-terpyridyl ligand is bonded tridentate. The approximate square planar coordination geometry around the metal center is consistent with structures of $\mathrm{Pt}(\mathrm{II})$ complexes. The piperidyl groups are located above and below the platinum center suggesting that the amine groups are available to stabilize the metal center upon oxidation. As in the case of $\mathrm{Pt}\left(\mathrm{pip}_{2}{ }^{-}\right.$ $\mathrm{NCN})(\mathrm{tpy})^{+}$, the electronic absorption spectra of [Pt(Z$\mathrm{pip}_{2} \mathrm{NCN}$ )(R-tpy) $]^{+}$exhibit a band at $\sim 550 \mathrm{~nm}$ assigned to a $\sigma(\mathrm{Pt}-\mathrm{N}) \rightarrow \pi^{*}$ (tpy) charge-transfer transition, resulting from the weak interaction of a piperidyl group with the metal center. $\mathrm{Pt}\left(\mathrm{Z}-\mathrm{pip}_{2} \mathrm{NCN}\right)\left(\mathrm{R}\right.$-tpy) ${ }^{+}$complexes undergo two-electron platinum centered oxidation near $0.4 \mathrm{~V}$ and two $\mathrm{Pt}(\mathrm{tpy})$ centered reductions near $-1.0 \mathrm{~V}$ and $-1.5 \mathrm{~V}$. The scan rate dependence of the peak currents of the oxidation and the first reduction processes for $\mathrm{Pt}\left(\mathrm{pip}_{2} \mathrm{NCN}\right)\left(t \mathrm{Bu}_{3} \text { tpy }\right)^{+}$gives $n_{\text {ox }} / n_{\text {red }}=1.8$.

Variation in the ligand substituents ( $\mathrm{Z}$ and $\mathrm{R}$ ) allows for tuning of the two-electron-oxidation process over a $260 \mathrm{mV}$ range. Whereby the $\mathrm{Z}$ substituents on the $\mathrm{pip}_{2} \mathrm{NCN}^{-}$ligand have a more substantial influence $(220 \mathrm{mV})$ on the oxidation potential than the R substituents $(40 \mathrm{mV})$ on the terpyridine ligand. In addition, the two reduction processes are tunable over a range of $230 \mathrm{mV}$ (first reduction step) and $290 \mathrm{mV}$ (second reduction step). The electron-withdrawing $\mathrm{NO}_{2}$ substituent shifts the twoelectron-oxidation potential anodically, whereas electrondonating MeO-shifts the redox potential cathodically. The electrochemical sensitivity to the nitro-substituent suggests that the redox tuning occurs predominantly through electronic induction at the $\mathrm{d}_{z^{2}}$ orbital.

\section{Conflicts of interest}

There are no conflicts to declare.

\section{Acknowledgements}

The authors would like to express their gratitude to Dr Janette Krause for help with characterization. We thank the National Science Foundation (Grant CHE0134975) and the Arnold and Mabel Beckman Foundation for support.

\section{References}

1 J. F. Young, J. A. Osborn, F. H. Jardine and G. Wilkinson, Chem. Commun., 1965, 131.

2 A. E. Shilov and G. B. Shul'pin, Russ. Chem. Rev., 1987, 56, 442.

3 A. F. Heyduk and D. G. Nocera, Science, 2001, 293, 1639.

4 H. Jude, J. A. K. Bauer and W. B. Connick, J. Am. Chem. Soc., 2003, 125, 3446.

5 R. Ramasamy, K. Masao and K. Akira, Bull. Chem. Soc. Jpn., 1991, 64, 1028.

6 M. Dakkach, X. Fontrodona, T. Parella, A. Atlamsani, I. Romeo and M. Rodrigues, Adv. Synth. Catal., 2011, 353, 231.

7 R. G. Finke, R. H. Voegeli, E. D. Laganis and V. Boekelheide, Organometallics, 1983, 2, 347.

8 W. J. Bowyer, J. W. Merkert, W. E. Geiger and A. L. Rheingold, Organometallics, 1989, 8, 191.

9 W. J. Bowyer and W. E. Geiger, J. Am. Chem. Soc., 1985, 107, 5657.

10 K. D. Plitzko, B. Rapko, B. Gollas, G. Wehrle, T. Weakley, D. T. Pierce, W. E. Geiger, R. C. Haddon and V. Boekelheide, J. Am. Chem. Soc., 1990, 112, 6545.

11 K. D. Plitzko, G. Wehrle, B. Gollas, B. Rapko, J. Dannheim and V. J. Boekelheide, J. Am. Chem. Soc., 1990, 112, 6556.

12 J. Merkert, R. M. Nielson, M. J. Weaver and W. E. Geiger, J. Am. Chem. Soc., 1989, 111, 7084.

13 J. Edwin and W. E. Geiger, J. Am. Chem. Soc., 1990, 112, 7104.

14 K. R. Mann, N. S. Lewis, V. M. Miskowski, D. K. Erwin, G. S. Hammond and H. B. Gray, J. Am. Chem. Soc., 1977, 99, 5525.

15 K. R. Mann, M. J. DiPierro and T. P. Gill, J. Am. Chem. Soc., 1980, 102, 3965.

16 W. J. Bowyer and W. E. Geiger, J. Electroanal. Chem. Interfacial Electrochem., 1988, 239, 253.

17 S. Chatterjee, PhD thesis, University of Cincinnati, 2009.

18 F. G. Baddour, M. I. Kahn, J. A. Golen, A. L. Rheingold and L. H. Doerrer, Chem. Commun., 2010, 46, 4968.

19 A. J. Blake, R. D. Crofts and M. Schroder, J. Chem. Soc., Dalton Trans., 1993, 2259.

20 A. J. Blake, R. O. Gould, A. J. Holder, T. I. Hyde, A. J. Lavery, M. O. Odulate and M. Schroder, J. Chem. Soc., Chem. Commun., 1987, 118.

21 J. Fornies, B. Menjon, R. M. Sanz-Carrillo, M. Tomas, N. G. Connelly, J. G. Crossley and A. G. Orpen, J. Am. Chem. Soc., 1995, 117, 4295. 
22 G. J. Grant, N. J. Spangler, W. N. Setzer, D. G. VanDerveer and L. F. Mehne, Inorg. Chim. Acta, 1996, 246, 31.

23 R. I. Haines, D. R. Hutchings and T. M. McCormack, J. Inorg. Biochem., 2001, 85, 1.

24 M. Matsumoto, M. Itoh, S. Funahashi and H. D. Takagi, Can. J. Chem., 1999, 77, 1638.

25 R. Uson, J. Fornies, M. Tomas, B. Menjon, R. Bau, K. Suenkel and E. Kuwabara, Organometallics, 1986, 5, 1576.

26 M. A. Watzky, D. Waknine, M. J. Heeg, J. F. Endicott and L. A. Ochrymowyzc, Inorg. Chem., 1993, 32, 4882.

27 H. Jude, PhD thesis, University of Cincinnati, 2004.

28 E. C. Constable, A. M. W. C. Thompson, D. A. Tocher and M. A. M. Daniels, New J. Chem., 1992, 16, 855.

29 R. A. Fallahpour, Eur. J. Inorg. Chem., 1998, 9, 1205.

30 S. Kuyuldar, PhD thesis, University of Cincinnati, 2009.

31 J. A. Bailey, M. G. Hill, R. E. Marsh, V. M. Miskowski, W. P. Schaefer and H. B. Gray, Inorg. Chem., 1995, 34, 4591.

32 R. Romeo, L. M. Scolaro, M. R. Plutino and A. J. Albinati, Organomet. Chem., 2000, 593-594, 403.

33 T. K. Aldridge, E. M. Stacy and D. R. McMillin, Inorg. Chem., 1994, 33, 722.

34 H. K. Yip, L. K. Cheng, K. K. Cheung and C. M. Che, J. Chem. Soc., Dalton Trans., 1993, 2933.

35 J. S. Field, R. J. Haines, D. R. McMillin and G. C. Summerton, J. Chem. Soc., Dalton Trans., 2002, 1369.

36 G. Arena, G. Calogero, S. Campagna, L. M. Scolaro, V. Ricevuto and R. Romeo, Inorg. Chem., 1998, 2763.

37 S. E. Hobert, J. T. Carney and S. D. Cummings, Inorg. Chim. Acta, 2001, 318, 89.

38 S. W. Lai, M. C. W. Chan, K. K. Cheung and C. M. Che, Inorg. Chem., 1999, 38, 4262.
39 H. Jude, J. A. Krause-Bauer and W. B. Connick, Inorg. Chem., 2002, 41, 2275.

40 J. H. K. Yip and J. J. Vittal, Inorg. Chem., 2000, 39, 3537.

41 W. B. Connick, V. M. Miskowski, V. H. Houlding and H. B. Gray, Inorg. Chem., 2000, 39, 2585.

42 T. W. Green, R. Lieberman, N. Mitchell, J. A. Krause Bauer and W. B. Connick, Inorg. Chem., 2005, 44, 1955.

43 D. K. Crites-Tears and D. R. McMillin, Coord. Chem. Rev., 2001, 211, 195.

44 A. Sarkar and S. J. Chakravorti, J. Lumin., 1995, 63, 143.

45 K. Huang and A. Rhys, Proc. - R. Soc. Edinburgh, Sect. A: Math. Phys. Sci., 1950, 204, 406.

46 M. G. Hill, J. A. Bailey, V. M. Miskowsk and H. B. Gray, Inorg. Chem., 1996, 35, 4585.

47 S. C. F. Lam, V. W. W. Yam, K. M. C. Wong, E. C. C. Cheng and N. Zhu, Organometallics, 2005, 24, 4298.

48 V. W. W. Yam, R. P. L. Tang, K. M. C. Wong and K. K. Cheung, Organometallics, 2001, 20, 4476.

49 M. Maestri, N. Armaroli, V. Balzani, E. C. Constable and A. M. W. C. Thompson, Inorg. Chem., 1995, 34, 2759.

50 M. K. Nazeeruddin, S. M. Zakeeruddin and K. Kalyanasundaram, J. Phys. Chem., 1993, 97, 9607.

51 A. J. Bard and L. R. Faulkner, Electrochemical Methods, Wiley, New York, 1980.

52 J. E. B. Randles, Trans. Faraday Soc., 1948, 44, 327.

53 A. Sevcik, Collect. Czech. Chem. Commun., 1948, 13, 349-377.

54 J. J. van Benschoten, J. Y. Lewis, W. R. Heineman, D. A. Roston and P. T. Kissinger, J. Chem. Educ., 1983, 60, 772.

55 R. L. Myers and I. Shain, Anal. Chem., 1969, 41, 980.

56 V. Balzani, A. Juris, F. Barigelletti, P. Belser and A. Von Zelewsky, Sci. Pap. Inst. Phys. Chem. Res., 1984, 78, 78. 